\title{
The eye cannot see what the mind does not know: female genital mutilation
}

\author{
Hanni Stoklosa, ${ }^{1,2,3}$ Nawal M Nour ${ }^{2,4}$
}

It is estimated that 200 million women have undergone female genital mutilation (FGM) and of these, 44 million are girls younger than $15 .{ }^{1} \mathrm{FGM}$ is the removal of part or all of the female genitalia or organs for non-medical reasons and often takes place under traumatic, unsterile conditions. FGM leads to medical and psychiatric complications for the affected woman herself, and can harm future generations who may suffer from FGM-related complications of labour. Immediately after the procedure a girl or woman may experience haemorrhaging, sepsis, urinary retention and sometimes death. In the long term, women who have experienced FGM may suffer from chronic menstrual issues, urinary tract infections, dyspareunia, post-traumatic stress disorder or depression. Moreover, FGM may lead to increased caesarean section rates, and some studies have demonstrated increased rates of infant death. ${ }^{2}$

FGM is a human rights violation, public health issue and form of interpersonal violence. Just as health professionals need to be equipped to respond to modern slavery, or human trafficking, domestic violence and sexual assault, they need to have the tools to care for those who have experienced FGM. ${ }^{3}$

In 2012, the United Nations outlined the important role the health sector should play in responding to and preventing FGM:

Member states are called on to:

... protect and support women and girls who have been subjected to female genital mutilations and those at risk, including by developing social and psychological support services and care, and to take measures to improve their health, including sexual and reproductive health, in order to assist women and girls who are subjected to the practice;

and to:

${ }^{1}$ Department of Emergency Medicine, Brigham and Women's Hospital, Boston, Massachusetts, USA ${ }^{2}$ Harvard Medical School, Harvard University, Boston, Massachusetts, USA

${ }^{3}$ Department of Medicine, Brigham and Women's Hospital, Harvard Medical School, Boston,

Massachusetts, USA

${ }^{4}$ Division of Global Obstetrics and Gynecology, Brigham and Women's Hospital, Boston, Massachusetts, USA

Correspondence to Dr Hanni Stoklosa, Brigham and Women's Hospital, Boston, MA 02115-6195, USA; hstoklosa@bwh.harvard.edu
... develop, support and implement comprehensive and integrated strategies for the prevention of female genital mutilations, including the training of social workers, medical personnel. ${ }^{4}$

The EMJ study by Fawcett and Kernohan, 'A retrospective analysis of 34 potentially missed cases of female genital mutilation in the emergency department (ED),' unfortunately reveals that the health sector is in early stages of FGM awareness. Among the 34 missed cases of FGM in this UK, ED-based study, the most striking are the FGM cases that were not discovered despite a documented genitourinary (GU) exam.

\section{WHO SHOULD BE TRAINED AND WHEN SHOULD TRAINING HAPPEN?}

The first step for identification of FGM to occur is systematic education of health professionals. While the practice of FGM is highest in certain racial and ethnic communities, because of increased international migration, clinicians practising anywhere across the globe may encounter a patient who has experienced FGM. Moreover, all clinicians, including nurses, advanced practice providers, physicians and social workers across specialties of general medicine, emergency medicine and behavioural health, should be prepared to care for women who have experienced FGM. ${ }^{6}$ Training should begin in health professional schools and should be incorporated along the entire health professional education continuum, including specialty training. If FGM is not on a healthcare provider's differential diagnosis, it will simply be missed.

\section{HOW SHOULD HEALTH PROFESSIONALS BE TRAINED TO IDENTIFY, CARE FOR AND PREVENT FGM?}

The mere knowledge of FGM is not sufficient. Despite the fact that obstetricians and gynaecologists in the UK generally have high levels of FGM awareness, most of the undetected FGM cases in Fawcett and Kernohan's study had their GU exams in the ED performed by obstetrics and gynaecology clinicians. ${ }^{5}$ This means we need to advance our medical education efforts from abstract knowledge of FGM to the next phase: towards the application of clinical tools to screen and care for patients who have undergone FGM. ${ }^{36}$
Some currently available clinical tools include the WHO's 'Care of girls and women living with female genital mutilation: a clinical handbook,' the FGM screening algorithm adopted by the Royal College of Emergency Medicine, and the UK's NHS' 'FGM Information Sharing system'. 257

The overarching principles of evidencebased, patient-centred and trauma-informed care must be used in shaping training for health professionals and creating response protocols. Current evidence-based practices are summarised in the 'WHO guidelines on the management of health complications from female genital mutilation.' Evidence from other complex social problems has shown us that the environment created for disclosure is often more important than the actual screening questions asked. ${ }^{8} \quad 9$ Screening should be done in a non-judgemental manner, in a private setting and with the use of interpretive services as needed. Patient-centred approaches for FGM are especially important, as each individual's cultural contexts are unique. For example, in some cultures, a woman's decision-making is expected to involve members of the family, especially her partner or female relatives.

Finally, health professionals can play a role in FGM prevention. In the postpartum period after delivering a daughter, a woman who has experienced FGM may be willing to engage in a conversation around the consequences of her daughter being cut. $^{2}$

Overall, we see Fawcett and Kernohan's article as the first step towards opening emergency clinicians' eyes and minds to FGM. ${ }^{1}$ Our hope is that its presence in the medical literature spurs future action and research so that this vulnerable patient population can receive the care it needs, and that FGM might ultimately be prevented.

Contributors HS wrote the first and second drafts and NMN provided substantive edits.

Funding This study was supported by Mary Ann Tynan Fellowship, Brigham and Women's Hospital, and Esther B Khan Fellowship, Brigham and Women's Hospital.

Competing interests None declared.

Patient consent Not required.

Provenance and peer review Commissioned; internally peer reviewed.

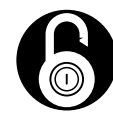

OPEN ACCESS 
Open access This is an open access article distributed in accordance with the Creative Commons Attribution Non Commercial (CC BY-NC 4.0) license, which permits others to distribute, remix, adapt, build upon this work non-commercially, and license their derivative works on different terms, provided the original work is properly cited, appropriate credit is given, any changes made indicated, and the use is non-commercial. See: http:// creativecommons.org/licenses/by-nc/4.0/.

(c) Author(s) (or their employer(s)) 2018. Re-use permitted under CC BY-NC. No commercial re-use. See rights and permissions. Published by BMJ.

\section{A Check for updates}

To cite Stoklosa H, Nour NM. Emerg Med J 2018:35:585-586.

Received 16 July 2018

Accepted 23 July 2018

Published Online First 17 August 2018

\section{(P) Linked}

- http://dx.doi.org/10.1136/emermed-2017-206649

Emerg Med J 2018;35:585-586

doi:10.1136/emermed-2018-207994

\section{REFERENCES}

1 UNICEF. Female genital mutilation/cutting: a global concern. New York: UNICEF, 2016. (accessed 12 Jul 2018).

2 World Health Organization. Care of girls and women living with female genital mutilation: a clinical handbook, 2018. (accessed 13 Jul2018).

3 Powell C, Dickins K, Stoklosa H. Training US health care professionals on human trafficking: where do we go from here? Med Educ Online 2017;22:1267980.

4 United Nations General Assembly. Intensifying global efforts for the elimination of female genital mutilations. 2012. http://unipd-centrodirittiumani.it/ public/docs/Risoluzione_67_146.pdf (accessed 12 Jul 2018).

5 Fawcett RJ, Kernohan G. A retrospective analysis of 34 potentially missed cases of female genital mutilation in the emergency department. Emerg Med J 2018;35:587-9.

6 Nour NM. Female genital cutting: clinical and cultural guidelines. Obstet Gynecol Surv 2004;59:272-9.

7 National Health Service. FGM Information sharing system. 2018. https://www.england.nhs.uk/ourwork/ safeguarding/our-work/fgm/ (accessed 15 July 2018).

8 Miller CL, Duke G, Northam S. Child sex-trafficking recognition, intervention, and referral: an educational framework for the development of health-careprovider education programs. I Human Trafficking 2016;2:177-200.

9 Hegarty KL, Taft AJ. Overcoming the barriers to disclosure and inquiry of partner abuse for women attending general practice. Aust N Z J Public Health 2001;25:433-7. 